\title{
sciendo
}

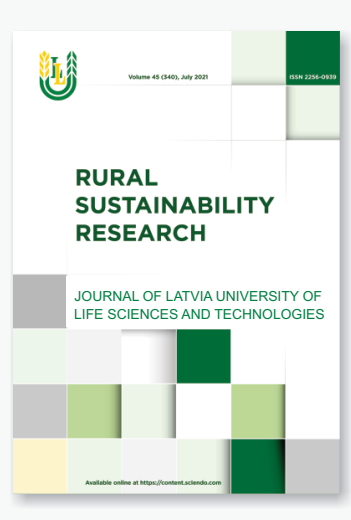

\section{A Case-study: Temperature Distribution and Heat Penetration in Steam-air Retort, Using Glass Jars and Retort Pouches}

\author{
*Evalds Raits ${ }^{1,2}$, Lasma Pinte ${ }^{2}$, Asnate Kirse-Ozolina ${ }^{1}$, Sandra Muizniece-Brasava ${ }^{1}$ \\ ${ }^{1}$ Latvia University of Life Sciences and Technologies, 22 Riga Street, Jelgava, Latvia \\ ${ }^{2}$ Kronis Ltd., 8 Darznieku street, Bauska, Latvia
}

\begin{abstract}
Retort thermal sterilization of canned food is a technology, which allows preserving food products by applying heat on packaged food in retorts (autoclaves) at temperatures up to $121^{\circ} \mathrm{C}$. The thermodynamics of the processes in the retort are influenced by the product stacking method in the basket and packaging material. The aims of this study were: 1) to analyse and compare temperature distribution (TD) and the slowest to heat location in the steam-air retort stacked with glass jars and with retort pouches; 2) to analyse and compare commercial product heat penetration (HP) characteristics in glass jars and retort pouches. Temperature measurements were performed with wireless thermocouples. The come-up time (heating phase) required to achieve in the retort temperature uniformity criteria of $\pm 0.5^{\circ} \mathrm{C}$, is $28 \mathrm{~min}$ when the retort is stacked with glass jars, and $24 \mathrm{~min}$ when the retort is stacked with retort pouches. Total calculated process time (holding phase), necessary to achieve the sterilization value ( $\mathrm{F}_{0}$ of $3 \mathrm{~min}$ ), for sample in glass jars was $67 \mathrm{~min}$, but in retort pouches $-62 \mathrm{~min}$. The overall sterilization process time difference between two considered packaging types was $9 \mathrm{~min}$, which is significant amount of time in the context of commercial processing. The study clearly shows the necessity to perform the Temperature Distribution and Heat Penetration study, as each packaging material, stacking method and product will affect sterilization process thermodynamics and, therefore, the overall process time and consequently - the safety of food product.
\end{abstract}

Key words: Process evaluation; process determination; CUT; holding time; autoclave processing.

\section{Introduction}

The main conditions for successfully produced food products include not only high quality goods and affordable prices, but also reliable, safe and aesthetically pleasing packaging. Various packaging materials are currently used for storing and identifying products, from traditional glass to innovative polypropylene with a barrier layer (Han, 2005). Food packaging contributes to extending the shelf life and maintaining the quality and safety of the food products (Kelsey, 1989).

Glass jars are widely used for packing foods and beverages. These have the advantages of very low interaction with the contents and visibility of the product. However, they require more careful processing and handling, as well as inner pre-treatment with steam.

Flexible retort pouches are a unique alternative packaging for sterile shelf-stable products that can withstand common thermal processing temperatures in canning industry, i.e. $120{ }^{\circ} \mathrm{C}$. Pouches are made of laminated materials that provide oxygen and moisture barrier (Simpson et al., 2019).

Retort packaging have numerous advantages in food processing industry in comparison with glass packaging easier logistics, lower weight, and more convenient handling in general. From the food production point of view, according to Brody et al., (2008), products packaged in pouches need less heat energy amount to achieve the 'commercial sterility`.

In the canning industry, thermal preservation processes are designed based on product $\mathrm{pH}$ to contain the production of the botulin toxin by Clostridium botulinum, as the toxin is not produced at $\mathrm{pH}<4.6$. Therefore, low-acid canned foods should receive increased attention in the prevention of Clostridium botulinum (Noronha, 1996). Therefore, it is necessary to give a scientific justification for such sterilization regime, which would preserve the culinary qualities of canned food, at the same time, would ensure the destruction of microorganisms that cause spoilage, i.e. achieved sterilization value $\left(\mathrm{F}_{0}\right) \geq 3 \min$ (Rawat, 2015).

Thermodynamics of the processes in retort are influenced by product stacking method in the basket, packaging material and product properties (Holdsworth \& Simpson, 2016). In liquid products, heat is transferred mainly by convection, and the temperature in the can rises faster due to the constant movement of product particles; therefore, the temperature 
difference inside the can is negligible. Products with a dense consistency are warmed up due to thermal conductivity; heating proceeds slowly due to the absence of transition of the product particles from heated to cold areas. As temperature difference between the retort and the packaging decreases - heat transfer rate decreases accordingly (AlBaali \& Farid, 2006).

Retort steam-air sterilization method consists of the following steps: basket with the packaged product loading, full basket placement into the retort, deaeration phase, heating the retort with steam (coming-up phase) until the set temperature, holding the set temperature in retort (holding phase) and application of cold water (cooling phase). The coming-up time is the time necessary to achieve uniform temperature in the retort. The process time (holding phase) for a commercial operation (sterilization process) is measured from the moment when retort reaches processing temperature, till the time when steam is discharged from the retort and cooling water is applied, i.e. the cooling phase has started. Duration of the sterilization process time is determined by the rate of heat transfer into the containers (AlBaali \& Farid, 2006).

Since there are no specific requirements in Latvia Republic legislation for canning facilities regarding the sterilization process designed for autoclaves, the aims of this study were:

1) to analyze and compare temperature distribution (TD) and the slowest to heat location in the steam-air retort OP-Panini SN4280 stacked with glass jars and with retort pouches.

2) to analyze and compare commercial product heat penetration (HP) characteristics in glass jars and retort pouches in the steam-air retort OP-Panini SN4280.

\section{Materials and Methods}

Packaging

In this study, glass (Table 1) and retort pouch packaging (Table 2) were used. Glass jars were manufactured by LLC Krasnoye Echo (Gus-Khrustalny, Russia).

Table 1

Physical properties of the glass jars

\begin{tabular}{ll}
\hline Property & Values \\
\hline Nominal capacity, ml & 500 \\
Full capacity, ml & $540 \pm 10$ \\
Height, mm: & $115 \pm 1 ;$ O88 \pm 1.5 \\
Diameter, mm & $88 \pm 1.5$ \\
wall thickness, not less than, mm & 1.2 \\
bottom thickness, not less than, mm & 2.0 \\
\hline
\end{tabular}

Retort pouches were manufactured by C. L. P Industries Ltd. "Tadbik" (Kibbutz Negba, Israel). Pouch material composition: lacquer $10 \mu \mathrm{m}$, polyethylene terephthalate $12 \mu \mathrm{m}$, aluminium $9 \mu \mathrm{m}$, biaxially oriented nylon $15 \mu \mathrm{m}$, polypropylene $80 \mu \mathrm{m}$.

Physical properties of the retort pouches

\begin{tabular}{ll}
\hline Property & Values \\
\hline Thickness, $\mu \mathrm{m}$ & 126 \\
Weight, g/m² & $147 \pm 11$ \\
Width size, mm & $160 \pm 2$ \\
Length size, mm & $210 \pm 2$ \\
Gusset height, mm & $43 \pm 1$ \\
Side seal width, mm & $8 \pm 1$
\end{tabular}




\section{Processing}

Experiments were performed at Kronis Ltd. (Bauska, Latvia), in the production-scale, horizontal steam - air retort OP-Panini SN4280 (Maranello MO, Italy). Steam inlet pipe was located lenghtwise on the bottom of the retort with inlet points between the baskets, and fan that is meant to distribute steam and ensure steam-air mixing - at the far end of the retort, near the $1^{\text {st }}$ basket (Fig. 2). Air inlet was located on the top of the retort, between the $2^{\text {nd }}$ and the $3^{\text {rd }}$ basket. Resistance thermometer (Pt100), which is used by the retort to control the process setpoints, was located on the top - between the $3^{\text {rd }}$ and the $4^{\text {th }}$ basket. Throughout the experiment, the following retort program setpoints were set the same for the jars and the pouches during the TD study:

1. preliminary step: steam inlet and outlet are open until the references Pt100), which controls the process, indicates 80 ${ }^{\circ} \mathrm{C}$;

2. come-up (CUT) phase: $15 \mathrm{~min}$ to $120^{\circ} \mathrm{C}$;

3. overshoot: 5 min at $120^{\circ} \mathrm{C}$;

4. holding phase: $20 \mathrm{~min}$ at $118^{\circ} \mathrm{C}$;

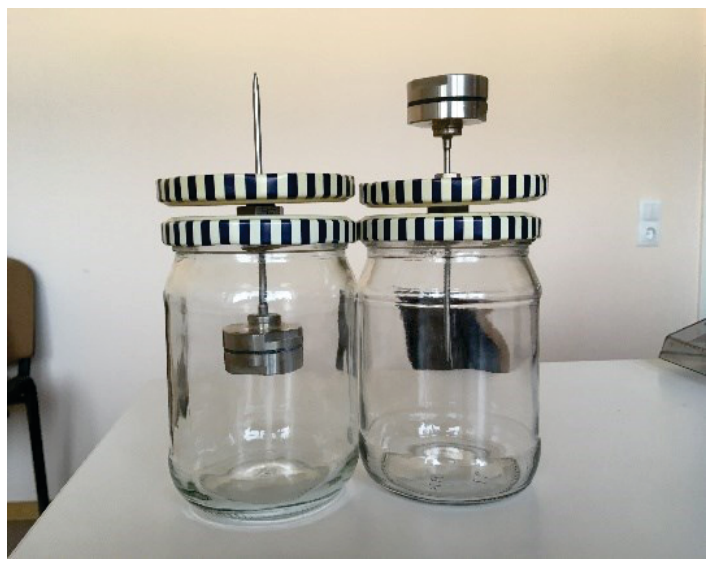

A
5. cooling phase: $25 \mathrm{~min}$, or untill the references packaging would achieve $50^{\circ} \mathrm{C}$.

HP study was performed with the same setpoints, except the holding phase $-60 \mathrm{~min}$ at $118^{\circ} \mathrm{C}$.

\section{Thermocouple fastening}

For this study, 20 T-type thermocouples with $10 \mathrm{~cm}$ long probes, and 1 pressure sensor combined with thermocouple were used (Tecnosoft, Mezzate MI, Italy). Temperature accuracy of the selected thermocouples was $\pm 0.2^{\circ} \mathrm{C}$.

During the TD study, temperature measuring devices (TMD) were located inside of the packaging, with temperature sensor located outside of the packaging, protruding through the divider sheets into the layer above, to measure the ambient temperature. For both glass (Figure 1a) and flexible packaging (Figure 1b), locking bolts (Tecnosoft, Mezzate MI, Italy) were used to fix and adjust the position of sensor. During the HP study, TMD sensor was located in the expected coldest zone of the packaging.

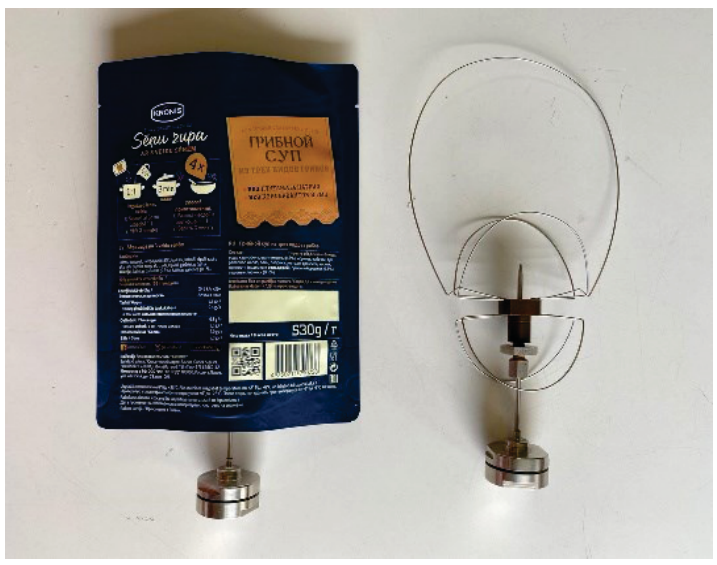

B

Figure 1. Thermocouple fastening in glass jars case (a) and retort pouch case (b).

\section{Products}

For TD study, packages were filled with water and used as a ballast during the sterilization, to ensure steam distribution flow in the retort similar to production conditions. For HP study, commercial product "Rassolnik" soup $(\mathrm{pH}=5.1)$ was used. The product was a thick soup concentrate, a mixture of fresh, pickled or salted vegetables with the addition of oil, tomato paste, salt, sugar, flour and spices. Retort pouches were filled with $530 \mathrm{~g}$, and the glass jars were filled with 470 $\mathrm{g}$ of the product.

\section{Temperature distribution (TD) studies}

TD studies were conducted in a retort using distributed TMDs to establish venting procedures, venting schedules, come-up requirements, temperature stability and uniformity, all of which are necessary to establish reproducible and reliable heating and cooling performance throughout the retort.

TD study was performed in three stages for both types of packaging:

1. During the first stage (Figure 2a), 18 temperature measurement devices (TMDs) were distributed in one basket from the top to the bottom. Four process cycles were performed. During each cycle the basket with TMDs was moved to the next position, starting at first position - the farthest from the door of the retort, which allows us to analyze temperature distribution through each basket in each position in the retort.

2. During the second stage (Figure 2b), 20 TMDs were divided between 4 baskets, located in the slowest part of the baskets, i.e. the lower part, which allows us to identify the slowest heated zone of the retort.

3. During the third stage (Figure 2c), 4 TMDs were located in the slowest heated zone of the basket, located in 
slowest heated position of the retort.

One TMD combined with pressure sensor was always located near the reference Pt100. Time-temperature data was gathered twice, but only the "worst case" data was considered in this work.

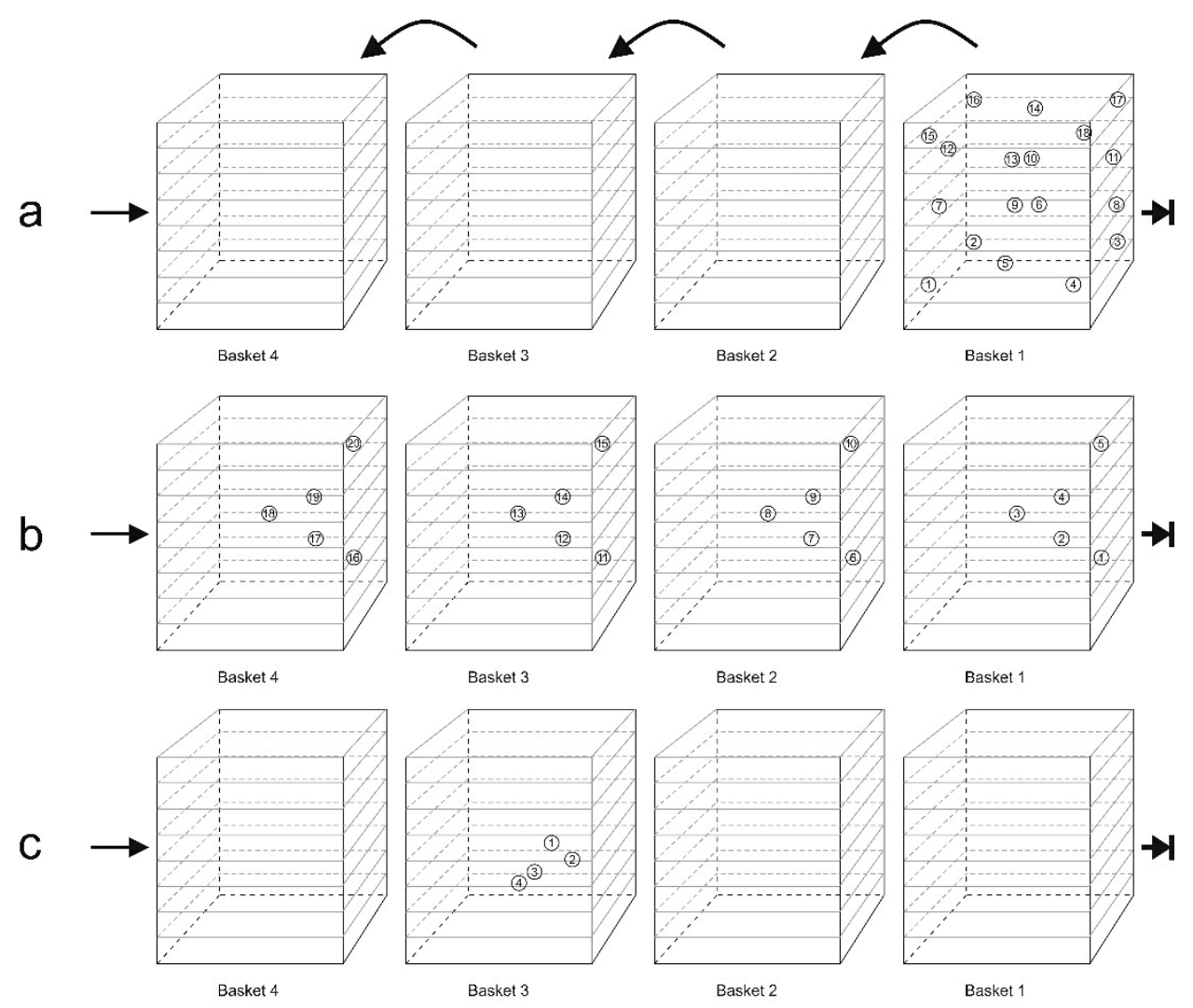

Figure 2. Thermocouple locations during the three stages of Temperature Distribution study for retort stacked with glass jars.

\section{Heat penetration (HP) studies}

HP studies were performed with the same ballast, as TD study. Time-temperature data were obtained by measuring temperature inside of the thermal center of the packaging filled with commercial product. Packages with TMDs were located in the slowest heated zone of the retort, defined during the TD study. Further heat penetration factors were calculated by Ball method (Ball, 1923), and consequently holding phase was defined by Stumbo method (Stumbo, 1973) with implemented apparent position numerical solution (APNS) method (Noronha, 1996). Time-temperature data was gathered twice, but only the "worst case" data was considered in this work.

\section{Dataprocessing}

Data obtained during the experiments was collected and analyzed with a computer using Ball 2.2 and Stumbo 2.2. Average values and standard deviation were obtained using Microsoft Excel v16. The heat penetration data was plotted using Ball 2.2 against time on a semi-log graph. The temperature difference (retort temperature minus core temperature of the product) was plotted on the log scale. The lag factor for heating $\left(j_{h}\right)$, slope of the heating curve $\left(f_{h}\right)$, lag factor for cooling $\left(j_{c}\right)$, slope of the heating curve $\left(f_{c}\right)$ - were determined from semi-log graph.

\section{Results}

Temperature distribution study in retort stacked with glass jars

Data analysis from the first stage of the experiment (Table 3 ) showed that the lower part of the basket was heated the slowest, which were the layers No. 2 to 6. Comparing TMD readings in the right side of the basket (i.e. considering point of view from the door) with the data from the left side, we can conclude that the right side of the basket was heated slower.

The second stage showed that the slowest heated TMDs were located in the layer No. 4 for the $1^{\text {st }}, 3^{\text {rd }}$ and $4^{\text {th }}$ basket, but in the $2^{\text {nd }}$ basket the slowest TMD was located in the layer No. 2. To achieve $\pm 0.5{ }^{\circ} \mathrm{C}$ temperature difference between the highest and the lowest temperature measurements, the change was made to prolong CUT for 5 min for the coldest TMD in $1^{\text {st }}$ basket, 9 min for the TMD in the $2^{\text {nd }}$ basket, and 11 min for the TMDs in the 2nd and 3rd basket. At the start of the holding phase, the TMD No. 6 , which is located in the $2^{\text {nd }}$ basket, had similar value as the TMD No. 12 in $3^{\text {rd }}$ basket. It was noted that after 1, 3 and $5 \mathrm{~min}$ of the holding stage, the difference between the retort temperature and the coldest point $(\Delta \mathrm{T})$ was higher for the thermocouples in the $3^{\text {rd }}$ basket. In spite of the fact that the same amount of time is necessary to 
heat the foregoing TMDs in the $2^{\text {nd }}$ and $3^{\text {rd }}$ basket, it is considered that the slowest heated zone is in the $3^{\text {rd }}$ basket,

between the layers 2 and 4, due to worse heating dynamic.

Table 3

Temperature data analysis for temperature distribution study in retort stacked with glass packaging

\begin{tabular}{|c|c|c|c|c|c|c|c|c|c|}
\hline Stage & $\begin{array}{l}\text { Basket } \\
\text { position }\end{array}$ & $\begin{array}{l}{ }^{1} \mathrm{~T}_{\text {std dev }}, \\
{ }^{\circ} \mathrm{C}\end{array}$ & $\begin{array}{l}{ }^{2} \mathrm{~T}_{\text {mean }}, \\
{ }^{\circ} \mathrm{C}\end{array}$ & $\begin{array}{l}{ }^{3} \mathrm{~T}_{\min }, \\
{ }^{\circ} \mathrm{C}\end{array}$ & $\begin{array}{l}{ }^{4} \Delta \mathrm{T}, \\
{ }^{\circ} \mathrm{C}\end{array}$ & $\begin{array}{l}\Delta \mathrm{T}+1 \\
\min ,{ }^{\circ} \mathrm{C}\end{array}$ & $\begin{array}{l}\Delta \mathrm{T}+3 \\
\min ,{ }^{\circ} \mathrm{C}\end{array}$ & $\begin{array}{l}\Delta \mathrm{T}+5 \\
\min ,{ }^{\circ} \mathrm{C}\end{array}$ & $\begin{array}{l} \pm 0.5^{\circ} \mathrm{C} \\
\min \end{array}$ \\
\hline \multirow[t]{4}{*}{$\mathrm{a}$} & 1 & 1.9 & 118.3 & 113.5 & 6.5 & 4.3 & 2.7 & 1.5 & 10 \\
\hline & 2 & 1.3 & 118.7 & 115.2 & 3.9 & 3.0 & 2.2 & 1.5 & 10 \\
\hline & 3 & 1.9 & 118.5 & 113.9 & 5.9 & 4.4 & 3.2 & 2.2 & 12 \\
\hline & 4 & 0.6 & 119.4 & 118.2 & 2.4 & 2.3 & 1.8 & 0.5 & - \\
\hline \multirow[t]{4}{*}{$\mathrm{b}$} & 1 & 0.3 & 119.1 & 118.5 & 1.1 & 0.9 & 0.8 & 0.5 & 5 \\
\hline & 2 & 1.4 & 116.8 & 114.4 & 5.1 & 3.8 & 2.6 & 1.7 & 11 \\
\hline & 3 & 1.3 & 115.8 & 114.6 & 5.0 & 4.1 & 3.1 & 2.0 & 11 \\
\hline & 4 & 1.4 & 116.9 & 115.6 & 4.0 & 3.5 & 2.3 & 1.3 & 9 \\
\hline $\mathrm{c}$ & 3 & 1.5 & 117.6 & 116.1 & 3.5 & 1.7 & 1.1 & 1.0 & 13 \\
\hline
\end{tabular}

${ }^{1}$ Standard deviation in temperature readings at the end of the coming-up time (CUT) phase; ${ }^{2}$ Mean between thermocouple readings at the end of the CUT; ${ }^{3}$ The lowest thermocouple reading at the end of the CUT; ${ }^{4}$ Temperature difference between reference thermocouple and the lowest reading in the retort;

The third stage of the experiment showed that despite the lower $\mathrm{T}_{\min }$ and $\Delta \mathrm{T}$ temperatures at the start of the overshoot, as well as after 1,3 and $5 \mathrm{~min}$, it still needed 13 more minutes to achieve $\pm 0.5^{\circ} \mathrm{C}$ difference between the highest and the lowest readings of the thermocouples in the retort.

Temperature distribution study in retort stacked with retort pouches

During the first stage of the TD study, basket-per-basket approach showed (Table 4) that the lowest mean temperature readings were achieved in the $2^{\text {nd }}$ and $3^{\text {rd }}$ basket. The slowest heated TMDs in these baskets were located in the front part of the $6^{\text {th }}$ and $8^{\text {th }}$ layers, while in the $4^{\text {th }}$ basket, the lowest temperature was achieved in the back side of the basket, in the $6^{\text {th }}$ layer. The lowest temperature of the basket in $1^{\text {st }}$ position was achieved in the $8^{\text {th }}$ layer. Despite the fact that the coldest thermocouple in the $3^{\text {rd }}$ basket at the start of the holding phase, have had higher temperature, than the thermocouple in the $2^{\text {nd }}$ basket - it took $3 \mathrm{~min}$ to achieve $\pm 0.5^{\circ} \mathrm{C}$ uniformity in the retort for the $3^{\text {rd }}$ basket, while for the $2^{\text {nd }}$ basket it took $2 \mathrm{~min}$.

During the second stage of the experiment, TMDs $(n=18)$ were divided between the $2^{\text {nd }}$ and the $3^{\text {rd }}$ baskets, and located in the layers 6 and 8. Four of the lowest temperature readings were achieved in the $3^{\text {rd }}$ basket $8^{\text {th }}$ and $6^{\text {th }}$ layers.

Table 4

Temperature data analysis for temperature distribution study in retort stacked with flexible packaging

\begin{tabular}{|c|c|c|c|c|c|c|c|c|c|}
\hline Stage & $\begin{array}{l}\text { Basket } \\
\text { position }\end{array}$ & $\begin{array}{l}{ }^{1} \mathrm{~T}_{\text {std dev }}, \\
{ }^{\circ} \mathrm{C}\end{array}$ & $\begin{array}{l}{ }^{2} \mathrm{~T}_{\text {mean }}, \\
{ }^{\circ} \mathrm{C}\end{array}$ & $\begin{array}{l}{ }^{3} \mathrm{~T}_{\min }, \\
{ }^{\circ} \mathrm{C}\end{array}$ & $\begin{array}{l}{ }^{4} \Delta \mathrm{T}, \\
{ }^{\circ} \mathrm{C}\end{array}$ & $\begin{array}{l}\Delta \mathrm{T}+1 \\
\min ,{ }^{\circ} \mathrm{C}\end{array}$ & $\begin{array}{l}\Delta \mathrm{T}+3 \\
\min ,{ }^{\circ} \mathrm{C}\end{array}$ & $\begin{array}{l}\Delta \mathrm{T}+5 \\
\min ,{ }^{\circ} \mathrm{C}\end{array}$ & $\begin{array}{l} \pm 0.5^{\circ} \mathrm{C} \\
\min \end{array}$ \\
\hline \multirow[t]{4}{*}{$\mathrm{a}$} & 1 & 0.1 & 118.6 & 118.4 & 0.4 & 0.4 & 0.2 & 0.1 & - \\
\hline & 2 & 0.2 & 118.1 & 117.8 & 0.9 & 0.6 & 0.4 & 0.3 & 2 \\
\hline & 3 & 0.3 & 118.9 & 118.2 & 1.3 & 0.8 & 0.5 & 0.3 & 3 \\
\hline & 4 & 0.2 & 119.1 & 118.6 & 0.9 & 0.6 & 0.4 & 0.2 & 1 \\
\hline b & 2,3 & 0.4 & 119.1 & 118.5 & 1.4 & 0.8 & 0.6 & 0.6 & 8 \\
\hline $\mathrm{c}$ & 3 & 1.5 & 117.6 & 116.1 & 3.5 & 1.7 & 1.1 & 1.0 & 13 \\
\hline
\end{tabular}


Standard deviation in temperature readings at the end of the coming-up time (CUT) phase; ${ }^{2}$ Mean between thermocouple readings at the end of the CUT; ${ }^{3}$ The lowest thermocouple reading at the end of the CUT; ${ }^{4}$ Temperature difference between reference thermocouple and the lowest reading in the retort;

During the third stage of the experiment, it was decided to compare temperature readings $(\mathrm{n}=18)$ between the layers No. 6 to 9 of the $3^{\text {rd }}$ basket. The lowest temperature readings were achieved in the middle-left part of the layer No. 8, followed by the middle-front part of the layer No. 9, and middle-left part of the layer No. 7. To achieve temperature uniformity in the retort, it was necessary to prolong the CUT phase of the sterilization cycle for $9 \mathrm{~min}$

\section{Heat penetration study}

The purpose of heat penetration studies is to determine heating and cooling behavior of a product/package combination in a specific retort system for the establishment of safe thermal processes to deliver commercially sterile products and to assist in evaluating process deviations.

One of the most precise and generally adapted method for sterilization process time (holding time) evaluation is the Stumbo formula method (Stumbo, 1973), which assumes that CUT contribution in total lethal effect is $42 \%$, which have been determined by Ball (Ball, 1923). A number of $42 \%$ is a "conservative estimate" (Holdsworth \& Simpson, 2016), and is only applicable to the cases with linear heating profile, which often do not correspond to the reality. Numerous studies have found different effectiveness coefficients, affected by the packaging material, reporting the contribution up to almost $80 \%$ (Ramaswamy \& Tung, 1986; Ramaswamy et al., 1993; Spinak \& Wiley, 1982).

For the product in each packaging type, heating rate index $\left(f_{h}\right)$, heating lag factor $\left(j_{h}\right)$, cooling rate index $\left(f_{c}\right)$ and cooling lag factor $\left(\mathrm{j}_{\mathrm{c}}\right)$ are presented (Table 5).

Table 5

Heat penetration data and calculated process times for thick soup concentrate "Rassolnik"

\begin{tabular}{|c|c|c|c|c|c|c|c|}
\hline Packaging & ${ }^{1} \mathrm{f}_{\mathrm{h}}, \min$ & ${ }^{2} \mathrm{j}_{\mathrm{h}}$ & ${ }^{3} f_{c}, \min$ & ${ }^{4} \mathrm{j}_{\mathrm{c}}$ & $\begin{array}{l}{ }^{5} \mathrm{CUT} \\
\text { contribution, } \%\end{array}$ & $\mathrm{~T},{ }^{\circ} \mathrm{C}$ & $\begin{array}{l}\text { Holding } \\
\text { time, min }\end{array}$ \\
\hline Glass jar & 59.7 & 2 & 75.7 & 2.08 & $57 \%$ & 118 & 67 \\
\hline Retort pouch & 71.6 & 1.18 & 70.4 & 2.18 & $61 \%$ & 118 & 62 \\
\hline
\end{tabular}

${ }^{1}$ Heating rate index; ${ }^{2}$ Heating lag factor; ${ }^{3}$ Cooling rate index; ${ }^{4}$ Cooling lag factor; ${ }^{5}$ Coming-up time.

Samples of the retort pouches showed higher heating rate index $\left(\mathrm{f}_{\mathrm{h}}\right)$ than product in the glass packaging, but lower heating lag factor $\left(\mathrm{j}_{\mathrm{h}}\right)$. Such difference in heating rate index is influenced by packaging material physical properties (thickness and thermal conductivity), as well as its practical usage.

\section{Discussion}

The slowest to heat zone of the retort in both cases was observed in the $3^{\text {rd }}$ basket. Such occurrence could be described by the retort principle of operation. Steam inlet pipe is located on the bottom of the retort, and fan that is meant to distribute steam - at the far end of the retort, near the $1^{\text {st }}$ basket. Since basket located in the $1^{\text {st }}$ position blocks the flow produced by the fan, and the basket in $4^{\text {th }}$ position is located where the flows meet, consequently receiving the best convection - the $2^{\text {nd }}$ and the $3^{\text {rd }}$ basket positions are expected to be slowest to heat.

It is logical to expect better steam flow on the outer side of the baskets than in the inner. It is also expected the upper part of the retort to be warmer than the bottom, because of natural convection of ambience, but the steam pipe location should level the differences. In case of the glass jars, the $3^{\text {rd }}-4^{\text {th }}$ layers were the slowest to heat in terms of the basket, while in the pouch case it was the $8^{\text {th }}$ layer. Such occurrence could be described by the density of the stacking method. In conductive heated materials, the "cold spot" is shifted lower from the center, while convective heated materials tend to have the cold spot in the geometric center (Campbell \& Ramaswamy, 1992; Joseph, Speers \& Pillay, 1996). It is fair to assume that retort pouch stacking method allows steam to penetrate the basket faster, thus shifting the "cold zone" upwards from the geometric center.

In comparison, retort stacked with flexible packaging showed the lower $\mathrm{T}_{\text {stddev }}$ in temperature readings $<0.5^{\circ} \mathrm{C}$ at the end of the CUT, while the $\mathrm{T}_{\text {stddev }}$ in the retort stacked with glass jars showed $<2.0{ }^{\circ} \mathrm{C}$. Such a fact was observed mainly because of the density of how the packaging was stacked in the basket. Glass jars were placed one on top of the other without any shift, divided with plastic divider plates with large holes, while retort pouches were placed horizontally on the shelves, forming $\sim 0.5 \mathrm{~cm}$ of headspace between the retort pouches and the shelf above. Such stacking method improves steam flow through the basket, therefore, enhancing the heat distribution throughout the retort. Nevertheless, the overall time required to achieve the temperature uniformity criteria of $\pm 0.5^{\circ} \mathrm{C}$ for the retort stacked with glass jars was $28 \mathrm{~min}$, while retort stacked with the retort pouches was $24 \mathrm{~min}$, which could be considered as small difference.

Since retort pouches are flexible, they form thinner layer of product that needs to be penetrated by heat, when placed horizontally in the autoclave basket, while glass jars diameter is constant, and has thicker layer of product that heat should penetrate. Total calculated process time (holding phase), necessary to achieve $\mathrm{F}_{0}=3 \mathrm{~min}$, for product in glass jars was $67 \mathrm{~min}$, but in retort packaging - $62 \mathrm{~min}$. Despite the larger heating rate index $\mathrm{f}_{\mathrm{h}}$ (time, necessary to elevate temperature for $1 \log _{10}$ ) and lower $f_{c}$ (time, necessary to lower temperature for $1 \log _{10}$ ), lower heating lag factor $\mathrm{j}_{\mathrm{h}}$ considerably affects total process time, resulting in lower necessary time to achieve $\mathrm{F}_{0}=3 \mathrm{~min}$. It is clearly seen that even retort pouches 
were filled with $530 \mathrm{~g}$ of product, while glass jars contained $470 \mathrm{~g}$ of product, nonetheless retort pouches showed $5 \mathrm{~min}$ faster result than glass packaging.

This study has certain limitations. Since heat transfer agent in steam-air retort is a mixture of air and steam - the mechanisms of heat transfer are mainly convection and condensation (Ramaswamy, 1983), the heating rate may be dependent on steam concentration in the heat transfer agent. Consequently, final achieved sterilization values may vary among expected, hence require heating rate distribution research in chosen retort.

\section{Conclusions}

The CUT required to achieve $\pm 0.5{ }^{\circ} \mathrm{C}$ temperature uniformity in the steam-air retort stacked with glass jars and retort packaging is 28 and $24 \mathrm{~min}$, respectively. The holding phase time (process time) necessary to achieve $\mathrm{F}_{0}$ $=3 \mathrm{~min}$ for the product in glass jars was $67 \mathrm{~min}$ and for the retort pouch was $62 \mathrm{~min}$. The overall sterilization process difference between two packaging types was $9 \mathrm{~min}$, which is considerable amount of time in the context of commercial processing.

The study clearly shows step-by-step process performing the Temperature Distribution and Heat Penetration study, as well as shows the necessity for them, as each packaging material, stacking method and product will affect sterilization process thermodynamics and, therefore, the overall process time and consequently - the safety of food product.

\section{References}

Al-Baali, A. G. A. G., \& Farid, M. M. (2006). Heat Transfer Principles. In G. V. Barbosa-Canovas (Eds), Food Engineering Series (pp. 17-23). Springer.

Ball, C. O. (1923). Thermal process time for canned food. Washington, USA: National Research Council of the National Academy of Sciences.

Brody, A. L., Bugusu, B., Han, J. H., Sand, C. K., \& McHugh, T. H. (2008). Innovative food packaging solutions. Journal of Food Science, 73(8), 107-116. DOI: $10.1111 / \mathrm{j} .1750-3841.2008 .00933$

Campbell, S., Ramaswamy H. (1992). Heating Rate, Lethality and Cold Spot Location in Air Entrapped Retort Pouches during Overpressure Processing. Journal offood science, 57, 485-489.

DOI: 10.1111/j.1365-2621.1992.tb05522.x

Han, J. H. (2005). New technologies in food packaging.
Overiew. In H. H. Jung (Eds), Innovations in Food Packaging (pp. 3-11). Elsevier.

Holdsworth, S. D., \& Simpson, R. (2016). Thermal Processing of Packaged Foods. Food Engineering Series. Boston, MA, USA: Springer.

Joseph, S., Speers, R., \& Pillay, V. (1996). Effect of head space variation and heat treatment on the thermal and rheological properties of nonagitated, conduction-heated materials. LWT-Food Science and Technology, 29, 556-560. DOI: $10.1006 /$ fstl.1996.0085

Kelsey, R. J. (1989). Packaging in Today's Society, 3rd Edition. Lancaster, PA, USA: Technomic Publishing Co., Inc.

Noronha, J. F. (1996). Improved procedures for designing, evaluating and optimising in-pack thermal processing of foods. Ph.D. thesis, Catholic University of Leuven, Belgium.

Ramaswamy, H. S., (1983). Heat transfer studies of steam/air mixtures for food processing in retort pouches. Ph.D. thesis, The University of British Columbia, Canada.

Ramaswamy, H. S., \& Tung, M. A. (1986). Modelling Heat Transfer in Steam/Air Processing of Thin Profile Packages. Canadian Institute of Food Science and Technology Journal, 19(5), 215-222. DOI: 10.1016/s0315-5463(86)71670-2

Ramaswamy, V., Desarbo, W. S., Reibstein, D. J., \& Robinson, W. T. (1993). An Empirical Pooling Approach for Estimating Marketing Mix Elasticities with PIMS Data. Marketing Science, 12(1), 103-124. DOI: $10.1287 / \mathrm{mksc} .12 .1 .103$

Rawat, S. (2015). Food Spoilage: Microorganisms and their prevention. Pelagia Research Library Asian Journal of Plant Science and Research, 5(4), 47-56.

Spinak, S. H., \& Wiley, R. C. (1982). Comparisons of the General and Ball Formula Methods for Retort Pouch Process Calculations. Journal of Food Science, 47(3), 880-884. DOI: $10.1111 /$ j.1365-2621.1982.tb12736.

Simpson, R., Ramirez, C., Jimenez, D., Almonacid, S., Nunez, H., Angulo, A. (2019). Simultaneous multiproduct sterilization: Revisited, exlored, and optimized. Journal of Food Engineering, 241, 149158. DOI: 10.1016/j.jfoodeng.2018.08.007

Stumbo, C. R. (1973). Thermobacteriology in Food Processing, 2nd ed. Bourlington, USA: Elsevier Science.

\section{Acknowledgements}

The authors would like to thank Mr. Frits Eckenhausen for training, comprehensive consultations during the study and provided software for calculations.

Present research leading to these results in accordance with the contract No. 1.2.1.1/18/A/002 between Latvian Food Competence Centre Ltd. and the Central Finance and Contracting Agency (08.05.2019) has been conducted by Kronis Ltd. with the support from the European Regional Development Fund (ERDF) within the framework of the project Latvian Food Industry Competence Centre. 